\title{
O CRITÉRIO DE POSITIVIDADE PARA A ANÁLISE IMUNOISTOQUÍMICA DA p53 NA CONFIRMAÇÃO DA DISPLASIA DO ESÔFAGO DE BARRETT FAZ DIFERENÇA?
}

\author{
César Vivian LOPES ${ }^{1}$, Júlio C. PEREIRA-LIMA², \\ Antônio Atalíbio HARTMANN³ ${ }^{3}$, Eunice TONELOTTO ${ }^{4}$ e Karina SALGADO 5
}

RESUMO - Racional - O esôfago de Barrett é uma complicação da doença do refluxo gastroesofágico com importante potencial de malignização. Relata-se que a expressão do marcador tumoral p53 se acentua com a progressão displasia-adenocarcinoma. Objetivo - Avaliar a expressão da p53 no epitélio de Barrett com presença ou não de displasia conforme dois critérios de positividade. Material e Métodos - O material foi constituído por biopsias endoscópicas de 42 doentes com esôfago de Barrett. Cortes histológicos foram corados pela hematoxilina-eosina, pelo PAS-alcian blue e avaliados quanto à expressão imunoistoquímica da p53. O diagnóstico de displasia foi firmado pela concordância entre três patologistas. Foram utilizados dois critérios de positividade para a p53: 1. a coloração de, pelo menos, metade dos núcleos e 2. o encontro de qualquer núcleo corado. Resultados - O número total de fragmentos foi de 229 , com média de 5,4 por paciente. A displasia foi detectada em seis (14,3\%) casos. Para diferentes critérios de positividade, a p53 foi detectada, respectivamente, em $5(13,9 \%)$ e 14 $(38,9 \%)$ com epitélio metaplásico não-displásico. Especificamente nos seis casos displásicos, a p53 foi detectada, conforme o critério de positividade, em um (16,7\%) e quatro $(66,7 \%)$ casos, respectivamente. Conclusões - Nesta pequena série, a expressão imunoistoquímica da $\mathrm{p} 53$, independente do critério de positividade, não foi de auxílio para a confirmação de alterações displásicas no esôfago de Barrett.

DESCRITORES - Esôfago de Barrett. Proteína p53.

\section{INTRODUÇÃO}

O esôfago de Barrett (EB) é uma condição adquirida, presente em até $2 \%$ dos pacientes submetidos a esofagogastroduodenoscopia e em $10 \%$ a $15 \%$ dos doentes crônicos de sintomas de refluxo duodenogastroesofágico ${ }^{(4,8,10)}$, na qual uma extensão variável do epitélio escamoso esofágico é substituído por um epitélio colunar glandular, contendo células caliciformes ${ }^{(8,22,26,31)}$.

A importância desta metaplasia reside no fato deste epitélio anômalo poder evoluir para o adenocarcinoma, com a doença sendo constatada, geralmente, em estádios avançados. A sobrevida média não costuma ultrapassar os 12 meses, com menos de $10 \%$ dos doentes contando com sobrevida superior a $5 \operatorname{anos}^{(7,26)}$.

Visto o adenocarcinoma apresentar incidência não desprezível e prognóstico reservado, recomenda-se vigilância endoscópica e histológica por toda a vida do paciente com epitélio de Barrett ${ }^{(26,31)}$. Quando da opção pelo programa de vigilância, a detecção da displasia ainda representa o padrão-ouro para a avaliação da progressão para o câncer ou para a detecção do próprio carcinoma in $\operatorname{situ}^{(18,26)}$. No entanto, embora considerada condição neoplásica inequívoca sobre certas circunstâncias, sua detecção apresenta certa ambigüidade no diagnóstico histopatológico, não apresenta nenhuma característica macroscópica específica e conta com imensa variação interobservador na avaliação histológica, além de poder apresentar resultados falso-negativos por erros de amostragem na coleta das biopsias ${ }^{(1,14,29)}$. Mais ainda, a história natural das displasias, tanto as de baixo quanto as de alto grau, não está totalmente esclarecida e a diferenciação celular com mudanças reacionais

Trabalho realizado no Programa de Pós-Graduação em Patologia, nos Serviços de Gastroenterologia e Patologia da Fundação Faculdade Federal de Ciências Médicas de Porto Alegre/Santa Casa e na Fundação Riograndense Universitária de Gastroenterologia, Porto Alegre, RS.

' Serviço de Clínica Médica da Universidade Luterana do Brasil; ${ }^{2}$ Departamento de Gastroenterologia da Fundação Faculdade Federal de Ciências Médicas de Porto Alegre (FFFCMPA); ${ }^{3}$ Santa Casa de Porto Alegre; ${ }^{4}$ Fundação Riograndense Universitária de Gastroenterologia; ${ }^{5}$ Departamento de Patologia da FFFCMPA, Porto Alegre, RS.

Endereço para correspondência: Dr. César Vivian Lopes - Rua Prof Cristiano Fischer 668 / 1001 - 91410-000 - Porto Alegre, RS. E-mail: cevele@terra.com.br 
secundárias à inflamação pode ser de difícil avaliação em casos de displasia de baixo grau ${ }^{(10)}$.

Assim, compreendendo-se a dificuldade em acompanhar com segurança os doentes com EB e de intervir precocemente antes da evolução para o adenocarcinoma, a literatura tem demonstrado grande apreço na busca de marcadores tumorais para detectar os casos de EB propensos ao desenvolvimento do câncer. Entre os marcadores em estudo, uma das opções é a p53, passível de avaliação pela imunoistoquímica, método relativamente simples, rápido, de custo acessível e disponível na maioria dos laboratórios de patologia ${ }^{(24)}$. Contudo, ainda não há consenso quanto ao valor deste marcador entre pacientes com displasia, bem como o critério de positividade a ser empregado.

Sendo assim, foi objetivo deste estudo avaliar, por meio de dois critérios de positividade, se a p53 apresenta ou não maior expressão em doentes com EB com alterações displásicas estabelecidas, pelo acordo no diagnóstico histopatológico entre três patologistas.

\section{MATERIAL E MÉTODOS}

O material, avaliado no laboratório de Patologia do Programa de Pós-Graduação em Patologia da Fundação Faculdade Federal de Ciências Médicas de Porto Alegre, RS, foi constituído por 42 blocos de parafina contendo múltiplos fragmentos de esôfago provenientes de biopsias endoscópicas. Foram utilizados como critérios de inclusão, presença de epitélio colunar especializado confirmado pela coloração com hematoxilina-eosina (H-E) e pelo PAS-alcian blue (PAS-AB), displasia confirmada por três patologistas, e ausência de adenocarcinoma.

\section{MÉTODOS}

\section{Exame histopatológico}

O material, fixado em formalina a $10 \%$, foi previamente submetido a processamento em soluções com concentração crescente de álcool e xilol e incluído em blocos de parafina. Destes, foram obtidos cortes histológicos de 3 micrômetros através de micrótomo manual, que foram depositados em banho-maria a $37^{\circ} \mathrm{C}$ e distendidos em duas lâminas: uma para coloração com H-E e outra para coloração com PAS-AB em pH ácido. A leitura das lâminas coradas com H-E e com PAS-AB para a confirmação da metaplasia intestinal e para a avaliação da presença e do grau da displasia, quando presente, foi realizada simultaneamente por dois examinadores (C.V.L. e A.A.H.) de maneira cega, em microscópio óptico (Olympus BX 40f-3), com ocular de 10x e objetivas de 10, 20 e 40x. A troca de opiniões só foi permitida quando da ocorrência de diagnósticos divergentes, com o intuito de se atingir um consenso.

A avaliação histológica foi realizada somente em biopsias endoscópicas intactas, providas de lâmina própria. As alterações com suspeita de displasia deveriam estar presentes em, pelo menos, mais de duas glândulas de proximidade ao epitélio escamoso adjacente. Quando mais de um fragmento da mesma biopsia endoscópica estivesse presente no mesmo corte, o grau de displasia da peça foi considerado o maior grau presente em qualquer dos fragmentos. Os critérios histopatológicos para a caracterização da displasia seguiram os critérios de MONTGOMERY et al. ${ }^{(25)}$, ou seja:

- displasia de baixo grau (DBG): núcleos aumentados, hipercromáticos, com contornos irregulares, respeitando a polaridade celular, acompanhados pela redução expressiva do número de células caliciformes e da mucina no ápice celular;

- displasia de alto grau (DAG): perda da polaridade nuclear e ausência de relação consistente entre os núcleos, demonstrando acentuada distorção da arquitetura glandular, com superfície mucosa de configuração viliforme, presença de pontes epiteliais intra-glandulares de aspecto cribiforme, além de ausência de células caliciformes.

Posteriormente, um terceiro patologista (K.S.) foi convidado para analisar as mesmas lâminas, seguindo os mesmos critérios, a fim de avaliar a concordância interobservador com os diagnósticos de displasia dos laboratórios de origem e com a leitura aqui realizada. Os casos indefinidos para displasia, quando presentes, foram agrupados com aqueles com DBG, conforme sugerido por MONTGOMERY et al. ${ }^{(25)}$. Foram considerados como verdadeiramente com displasia os casos concordantes entre três diferentes patologistas.

\section{Reações de imunoistoquímica}

Para o estudo da expressão da p53 foi empregada a técnica da estreptavidina-biotina-peroxidase. Cortes de 3 micrômetros de espessura foram fixados em lâminas silanizadas e armazenados à temperatura ambiente por, no máximo, 48 horas. Para a recuperação antigênica foi utilizado o calor úmido em banho-maria. $\mathrm{O}$ anticorpo primário foi o anticorpo monoclonal de camundongo contra a p53 humana (clone DO-7, DAKO Corporation, Carpinteria, CA, EUA). O cromógeno utilizado foi a diaminobenzidina. A diluição adequada do anticorpo primário foi 1:800. O controle positivo foi o carcinoma de mama. Por sua vez, como controle negativo, foi utilizada uma lâmina com cortes teciduais, sem o emprego do anticorpo primário durante o processamento do material. A avaliação da expressão imunoistoquímica do material analisado também foi realizada de maneira cega por dois dos autores desta casuística (A.A.H. e C.V.L.), de forma independente. Dois critérios de positividade foram empregados: 1. a forte coloração acastanhada nuclear de, no mínimo, metade das células e 2 . a coloração nuclear de qualquer número de células em campo de grande aumento (400x).

\section{Análise estatística}

Um $P<0,05$ foi considerado significativo para todos os procedimentos estatísticos do estudo. A análise de variáveis categóricas empregou o teste do Qui-quadrado. A comparação de médias empregou o teste $t$ de Student. A reprodutibilidade intra e interobservador quanto à positividade para a p53, utilizou o teste Kappa. Com o emprego deste teste, quatro possibilidades de acordo entre diferentes leituras poderiam ser obtidos: muito bom $(0,81-1)$, bom $(0,61-0,80)$, razoável $(0,41-0,60)$ e fraco $(0,01-0,40)$. Os dados foram processados e analisados com o 
auxílio do programa SPSS (SPSS Inc., Chicago, EUA), versão 10.0 para Windows.

O presente estudo foi apreciado pelo Comitê de Ética em Pesquisa da Santa Casa de Porto Alegre, tendo sido aprovado no dia 7 de maio de 2002 e protocolado sob no 434/02.

\section{RESULTADOS}

\section{Características da população estudada}

A população foi constituída por 42 pacientes, sendo 27 homens e 15 mulheres, com média etária de 55,8 (19-84) anos.

A extensão média do epitélio metaplásico foi de $3,4 \mathrm{~cm}$ e o número total de fragmentos provenientes das biopsias endoscópicas foi de 229, com média de 5,4 (1 a 18) fragmentos por paciente.

\section{Graduação da displasia}

O diagnóstico de displasia resultante da análise individual do mesmo grupo de lâminas por cada patologista variou de $21,4 \%$ a $54,8 \%$, com maioria sendo rotulada como DBG $(88,9 \%$ a $95,6 \%)$. Para análise do estudo foram considerados como pacientes com displasia os casos concordantes entre os três patologistas. Assim, a displasia foi constatada em seis casos, sendo de baixo grau em cinco casos e de alto grau em apenas um caso, perfazendo $14,3 \%$ da amostra.

\section{Expressão da p53 no esôfago de Barrett}

Antes da avaliação da expressão imunoistoquímica da p53 no $\mathrm{EB}$, alguns fatores de confusão para sua expressão foram revisados. A idade, o sexo masculino e a extensão do epitélio metaplásico não influenciaram a positividade da p53 $(P>0,05)$.

A reprodutibilidade tanto intra, quanto interobservador, para a expressão da p53 com qualquer critério de positividade foi muito boa (Kappa $>0,80$ ).

Ao se considerar como critério de positividade, pelo menos, metade dos núcleos corados, a p53 foi detectada no EB, com ou sem displasia, em $6(14,3 \%)$ dos 42 casos. Por sua vez, ao se considerar como critério de positividade a presença de qualquer número de núcleos corados, a p53 foi detectada em 18 (42,8\%) casos. Especificamente para os com epitélio metaplásico nãodisplásico, com os diferentes critérios de positividade, a p53 foi detectada, respectivamente, em $5(13,9 \%)$ e $14(38,9 \%)$ casos.

\section{Expressão da p53 no epitélio de Barrett com displasia}

Antes da avaliação da expressão imunoistoquímica da p53 no epitélio metaplásico com displasia, algumas variáveis foram testadas para verificar sua influência no processo displásico. A idade, o sexo masculino, o número de fragmentos e a extensão do epitélio metaplásico não influenciaram a presença de displasia $(P>0,05)$.

Entre os seis casos displásicos, quando da necessidade de, pelo menos, metade dos núcleos corados como critério de positividade, a p53 foi detectada em apenas um (16,7\%) caso com DBG. Ao se avaliar qualquer expressão da proteína entre os pacientes com displasia, quatro $(66,7 \%)$ casos expressaram a p53, três com DBG e outro com DAG (Tabela 1).
TABELA 1 - Expressão imunoistoquímica da p53 em pacientes com displasia no esôfago de Barrett segundo dois critérios de positividade

\begin{tabular}{cccccc}
\hline \multirow{2}{*}{$\begin{array}{c}\text { Critério de } \\
\text { positividade }\end{array}$} & \multicolumn{2}{c}{ Displasia presente } & \multicolumn{2}{c}{ Displasia ausente } & \multirow{2}{*}{$P$} \\
\cline { 2 - 5 } & p53 pos & p53 neg & p53 pos & p53 neg & \\
\hline$*$ & $1(16,7 \%)$ & 5 & $5(13,9 \%)$ & 31 & 1,00 \\
$* *$ & $4(66,7 \%)$ & 2 & $14(38,9 \%)$ & 22 & 0,37 \\
\hline $\begin{array}{l}\text { Positividade imunoistoquímica para a p53: } \\
* \text { Pelo menos metade dos núcleos corados } \\
* * \text { Qualquer número de núcleos corados }\end{array}$ & & & & \\
\end{tabular}

\section{DISCUSSÃO}

Apesar de a metaplasia intestinal, quando francamente presente, ser um diagnóstico com adequada reprodutibilidade ${ }^{(20)}, \mathrm{o}$ mesmo não ocorre para as displasias ${ }^{(1,10,14,21,29)}$, ponto de extrema relevância na tomada de decisões quanto ao acompanhamento clínico e à opção terapêutica entre doentes com EB.

$\mathrm{Na}$ experiência dos autores deste estudo ${ }^{(21)}$, em cada uma das leituras realizadas por diferentes patologistas, a displasia foi detectada, em média, em um terço dos casos (39\%), oscilando de $21 \%$ a $52 \%$. Quando a displasia esteve presente, esta foi de baixo grau em $92 \%$ dos casos. Apesar da plena concordância para a displasia entre os diferentes patologistas ter sido de apenas $14 \%$, este índice beira a real prevalência da displasia em diferentes séries ${ }^{(27,33)}$.

Procurando contribuir na confirmação da displasia e na predição do risco para degeneração maligna, a expressão imunoistoquímica da 553 constitui uma das maiores experiências sobre o tema. A p53 é ativada sobretudo pelo dano ao DNA, garantindo a manutenção da estabilidade genômica e suprimindo a carcinogênese pela indução ou repressão da transcrição de genes envolvidos na regulação do ciclo celular, no reparo do DNA e na indução da apoptose quando o dano celular é irreversível ${ }^{16,}$ ${ }^{19)}$. Nas neoplasias malignas epiteliais, como no adenocarcinoma oriundo do EB, as mutações da p53 são comumente encontradas, com cerca da metade de todos os casos com alguma forma de mutação ${ }^{(16)}$. Uma vez alterada, a p53 perde sua capacidade de interação ao DNA, assim permitindo a proliferação de células com instabilidade genômica, etapa primordial para a progressão ao câncer ${ }^{(5,12)}$. Além disso, ao contrário da proteína nativa, a proteína mutante apresenta maior expressão e conta com meiavida mais prolongada, tendo maior possibilidade de ser detectada pela imunoistoquímica ${ }^{(16)}$.

O emprego de anticorpos específicos contra a p53 revela-se um meio indireto para a detecção de mutações, embora ainda haja discordância entre a hiperexpressão da proteína anômala e a verdadeira presença de mutações, sem a hiperexpressão da p53 contar com um limiar abaixo do qual a associação entre a detecção imunoistoquímica da proteína e a mutação do material genético seja perdida ${ }^{(19)}$. Contudo, os critérios de positividade para sua detecção são extremamente divergentes, ainda não havendo um consenso. Especificamente quanto ao melhor anticorpo para a detecção da proteína de casos com mutações, BAAS et al. ${ }^{(2)}$ avaliaram seis anticorpos em neoplasias colorretais com mutações confirmadas pela reação em cadeia da polimerase. Na presença de mutações do gene TP53, o anticorpo monoclonal DO-7 demonstrou 
os melhores resultados quanto à detecção nuclear da proteína anômala, com sensibilidade de $67 \%$ e especificidade de $90 \%$. Este estudo é único pela avaliação de diferentes anticorpos também empregados rotineiramente na avaliação da p53 no EB. Ainda sobre o tema, BIAN et al. ${ }^{(3)}$ compararam diferentes mutações avaliadas através da PCR, com a expressão da proteína mutante, avaliada pela imunoistoquímica com o mesmo anticorpo. Houve concordância dos resultados entre os dois métodos tanto no adenocarcinoma ( $57 \%$ vs $67 \%$ ), como na DAG ( $77 \%$ vs $85 \%$ ). Por sua vez, não houve concordância adequada entre os métodos na DBG (29\% vs 71\%), que representou $78 \%$ dos resultados positivos por imunoistoquímica naqueles sem mutações, quando avaliados pela PCR. Desta maneira, a detecção imunoistoquímica da p53, independente do critério de positividade empregado, ainda não teve definida sua real aplicabilidade no EB. Mesmo com o emprego de um mesmo anticorpo (clone DO-7), a literatura demonstra achados conflitantes, podendo culminar com sobreposição ou mesmo perda de resultados positivos. Sem padrões definidos, os critérios variam desde a presença de qualquer núcleo corado, até a utilização de complicadas escalas de quantificação com valorização do percentual de núcleos corados, sua distribuição e intensidade de coloração (Tabela 2).

TABELA 2 - Expressão imunoistoquímica da p53 conforme o grau de displasia em pacientes com esôfago de Barrett com o emprego do anticorpo primário monoclonal DO-7 e diferentes critérios de positividade

\begin{tabular}{|c|c|c|c|c|}
\hline \multirow[b]{2}{*}{ Autores } & \multirow{2}{*}{$\begin{array}{c}\text { Critério de } \\
\text { positividade } \\
\text { (núcleos corados) }\end{array}$} & \multicolumn{3}{|c|}{ Expressão da p53(\%) } \\
\hline & & $\begin{array}{l}\text { Ausência } \\
\text { displasia }\end{array}$ & $\begin{array}{c}\text { Displasia } \\
\text { baixo grau }\end{array}$ & $\begin{array}{l}\text { Displasia } \\
\text { alto grau }\end{array}$ \\
\hline Bian et al. ${ }^{(3)}$ & $>10 \%$ & -- & 71 & 85 \\
\hline Illueca et al. ${ }^{(15)}$ & $\begin{array}{c}1+:<25 \% \\
2+: 25 \%-50 \% \\
3+: 50 \%-75 \% \\
4+:>75 \%\end{array}$ & 15 & 30 & 57 \\
\hline Krishnadath et al. ${ }^{(17)}$ & $>10 \%$ & 6 & 28 & 89 \\
\hline Symmans et al. ${ }^{(32)}$ & $\begin{array}{c}\text { Baixo: }<50 \% \\
\text { Alto: }>50 \%\end{array}$ & 0 & 37 & 20 \\
\hline Wu et al. ${ }^{(34)}$ & $>50 \%$ & 5 & 31 & 71 \\
\hline
\end{tabular}

SYMMANS et al. ${ }^{(32)}$, empregando como critério de positividade um limiar de $50 \%$ ou mais dos núcleos corados, não detectaram a p53 no EB não-displásico e sim em 30\% dos com displasia, sendo $37 \%$ nos casos com DBG e $20 \%$ entre os com DAG. Por sua vez, embora com critérios semelhantes, WU et al. ${ }^{(34)}$ detectaram a p53 no EB não-displásico em 5\% dos casos, na DBG em 31\% dos casos e em $71 \%$ dos com DAG. ILLUECA et al. ${ }^{(15)}$, utilizando escala com quatro intervalos de $25 \%$ dos núcleos corados como critério de positividade, detectaram a p53 no EB não-displásico em $15 \%$ dos casos, perante $30 \%$ entre os com DBG e $57 \%$ nos casos com DAG, embora predominantemente com menos de $25 \%$ dos núcleos corados. Já com o emprego de um critério de positividade mais abrangente, com pelo menos $10 \%$ dos núcleos corados, o EB não-displásico expressou a p53 em $6 \%$ dos casos, com cifras elevando-se para $28 \%$ e $89 \%$, respectivamente, naqueles DBG e $\mathrm{DAG}^{(17)}$. Com o mesmo critério, BIAN et al. ${ }^{(3)}$ não detectaram a p53 no Barrett não-displásico, porém a detectaram em 71\% dos com DBG e em $85 \%$ dos com DAG.

Desta maneira, visto ainda não se contar com padrões uniformes para definir a positividade da p53, optou-se pelo emprego de dois critérios para definição da positividade da reação imunoistoquímica: um abrangente, de leitura muito fácil e com adequada reprodutibilidade, sendo a detecção de qualquer núcleo fortemente corado no epitélio metaplásico; o outro, mais restritivo, porém sem grandes dificuldades inerentes ao estabelecimento de múltiplas escalas numéricas de graduação, que poderiam acarretar maior divergência tanto intra, como interobservador $^{(6)}$, foi a presença de, pelo menos, metade dos núcleos corados. Após o estabelecimento dos critérios de positividade, a reprodutibilidade para a expressão da p53 com qualquer critério, tanto intra quanto interobservador, demonstrou resultados adequados.

Definido o anticorpo a ser empregado, o aspecto numérico da expressão da p53 parece ser o componente mais importante quando da quantificação da expressão da proteína, talvez mais do que a intensidade da coloração ${ }^{(11)}$. A ocorrência de poucas células fortemente coradas não parece correlacionar com anormalidades moleculares da p53. Elas podem representar a atividade habitual da p53 nativa em que a proteína se acumula em resposta a erros genéticos espontâneos. Por sua vez, a presença de forte coloração na maioria das células é freqüentemente associada a mutações ${ }^{(2,}$ 11). Desta forma, definidos os critérios de quantificação, optou-se por valorizar apenas o percentual de núcleos corados e não sua intensidade de coloração.

No presente estudo, definidos os critérios de positividade, a p53 foi detectada no epitélio metaplásico em, respectivamente, $14 \%$ a $43 \%$ dos doentes com EB segundo critério de positividade com, pelo menos, metade dos núcleos corados, ou com qualquer número de núcleos corados. Para o epitélio sem displasia, a p53 foi detectada em $14 \%$ a $39 \%$ conforme o critério de positividade. Já para aqueles com displasia, o marcador foi detectado em $16,7 \%$ a $66,7 \%$ dos casos.

POLKOWSKI et al. ${ }^{(28)}$ também procurando melhorar a discriminação entre a ausência de displasia com a DBG, demonstraram que a p53 não foi de auxílio para tal distinção, enfatizando o elevado percentual de falso-positivo e falsonegativo na ausência de avaliação do gene TP53. Desta maneira, também a detecção da p53, independente do critério de positividade empregado, ainda não teve definida sua real aplicabilidade no EB.

KUBBA et al. ${ }^{(19)}$, em revisão avaliando a expressão nuclear média da p53 no EB, detectaram a p53 em 3\% (0\% a 6\%) dos pacientes sem displasia, em quase $22 \%(0 \%$ a $58 \%)$ dos com DBG, e em 70\% (33\% a 100\%) dos com DAG. As cifras deste estudo são bem diferentes das de BIAN et al. ${ }^{(3)}$, embora também compartilhem a maior expressão da proteína entre os pacientes com DAG. Ainda assim, a proteína foi detectada em pouco mais de $6 \%$ dos com metaplasia intestinal sem displasia, que não foi encontrada em população semelhante no estudo de BIAN et al. ${ }^{(3)}$. Tal fato poderia dever-se aos mais de 660 pacientes reunidos nos 
14 estudos avaliados por KUBBA et al. ${ }^{(19)}$ a respeito da expressão imunoistoquímica da p53.

Neste estudo, diferente dos achados de BIAN et al..$^{(3)}$, a p53 não foi de valor para a confirmação dos diagnósticos suspeitos de DBG ou mesmo de DAG à histologia. A p53 foi detectada em um único caso (20\%) de DBG, quando avaliado com critério de positividade mais restritivo, dados estes semelhantes aos de KUBBA et al. ${ }^{(19)}$ e de BIAN et al..$^{(3)}$, com detecção da p53 em $80 \%$ dos casos com DBG, quando do emprego de critério mais abrangente. No entanto, a expressão no epitélio metaplásico não-displásico foi acentuada, variando de $14 \%$ a $39 \%$, segundo o critério de positividade, diferente do encontrado por outros autores ${ }^{(3,5,12)}$. Tal achado não permite a distinção entre a proteína mutante em focos ainda sem displasia à avaliação histopatológica, conforme salientado por ILLUECA et al. ${ }^{(15)}$, e a proteína nativa com maior expressão em focos com inflamação acentuada ${ }^{(9,13)}$.

Especificamente quanto à expressão da $\mathrm{p} 53 \mathrm{em}$ doentes com DAG, apesar da pequena casuística desta série, para se tecer maiores considerações, o único caso com diagnóstico concordante entre os três patologistas que avaliaram o caso, expressou a p53 apenas quando empregado critério de positividade mais abrangente, tendo resultado negativo ao empregar-se metade dos núcleos corados para definir a positividade da reação. Tal achado, no entanto, encontra respaldo na literatura. SYMMANS et al. ${ }^{(32)}$ detectaram a p53 em apenas $20 \%$ dos doentes com de DAG. Por sua vez, ILLUECA et al. ${ }^{(15)}$ não demonstraram a proteína em $43 \%$ dos pacientes com DAG, mesmo quando da necessidade de qualquer número de núcleos corados para definir a positividade da reação. Entre os casos expressando a proteína, nenhum ultrapassou o limiar de $50 \%$ dos núcleos corados, achado similar em três dos casos displásicos desta série, sendo um com DAG. Fica claro, então, que os critérios de positividade podem apresentar resultados conflitantes em diferentes estudos, embora costumem respeitar a maior expressão da p53 quanto maior o grau de displasia. Ainda assim, na experiência dos mesmos autores, embora a prevalência da $\mathrm{p} 53$ entre os doentes com DBG tenha sido o dobro daquela observada entre os sem displasia, o padrão de positividade foi idêntico, ficando exclusivamente às custas do diagnóstico histopatológico adequado à distinção entre os dois grupos. Contudo, na literatura ${ }^{(1,10,14,29)}$ e na experiência dos autores do presente estudo ${ }^{(21)}$, o diagnóstico histopatológico, sobretudo para a DBG, ainda está longe de se mostrar ferramenta adequada, vista a precária reprodutibilidade tanto intra, como interobservador.

A pouca aplicabilidade na prática clínica da avaliação da p53 no EB com suspeita de displasia à avaliação histopatológica, já encontra respaldo na literatura ${ }^{(18,23)}$, havendo grupos contraindicando formalmente o emprego da imunoistoquímica para a avaliação do marcador tumoral ${ }^{(30)}$. Na procura de um marcador ideal, métodos mais laboriosos e ainda não disponíveis na maioria dos laboratórios de patologia, como a citometria de fluxo com estudo da tetra e/ou da aneuploidia, bem como a avaliação da perda da heterozigosidade para o braço curto do cromossoma 17 , responsável pela síntese da p53, demonstram resultados mais promissores e com melhor reprodutibilidade ${ }^{(18,23,30)}$.

\section{CONCLUSÃO}

Apesar do pequeno número de casos com displasia no EB desta casuística, esta prevalência foi obtida após estabelecimento de rígidos critérios diagnósticos e consenso entre três patologistas com experiência no trato gastrointestinal, refletindo a verdadeira experiência em outras séries. Acreditando estar trabalhando com verdadeiros casos com alterações displásicas em um centro de referência para a análise imunoistoquímica, pode-se concluir que a imunoistoquímica para a $\mathrm{p} 53$, pelo menos com estes dois critérios de positividade - qualquer núcleo corado ou, pelo menos, metade deles corados - não é de auxílio para a confirmação da displasia no epitélio metaplásico e, por conseguinte, para a predição do risco de degeneração maligna.

Novos estudos com maior número de pacientes e seleção criteriosa daqueles com displasia deveriam ser conduzidos para esclarecer definitivamente este importante tema.

Lopes CV, Pereira-Lima JC, Hartmann AA, Tonelotto E, Salgado K. Does positive criterium for p53 immunohistochemical analysis in the confirmation of Barrett's dysplasia make difference? Arq Gastroenterol 42(4):233-8.

ABSTRACT - Background - Barrett's esophagus is the most serious complication of the gastroesophageal reflux disease and presents a malignant potential. The expression of the tumoral marker p53 increases with the dysplasia-adenocarcinoma sequence. Aims - To evaluate the p53 expression in Barrett's esophagus with or without dysplasia according to the two positive immunostaining criteria. Material and Methods - The material was constituted by endoscopic biopsy specimens from 42 patients with Barrett's esophagus. Sections of formalinfixed and paraffin-embedded biopsies were stained with hematoxylin-eosin, PAS-alcian blue and evaluated the p53 immunohistochemical expression. Two p53 immunostaining criteria were utilized: 1 . the staining of, at least, half of the nuclei, and 2. the staining of any nucleus. The diagnosis of dysplasia was confirmed by the agreement between three pathologists. Results - The total number of tissue specimens was 229, with an average of 5.4 specimens per patient. Dysplasia, with agreement for all pathologists examining the same set of slides, was detected in six (14.3\%) cases. According to the two different p53 immunostaining criteria, the protein was detected in non-dysplastic Barrett's metaplasia, respectively, in 5 (13.9\%) and 14 (38.9\%) patients. Specificaly in the six dysplastic cases, p53 was detected, according to the immunostaining criteria, in one (16.7\%) and four $(66.7 \%)$ cases, respectively. Conclusions - In this group, p53 immunohistochemical expression, regardless of positive criteria take into account, was not useful for detecting dysplasia in Barrett's esophagus.

HEADINGS - Barrett esophagus. Protein p53. 


\section{REFERÊNCIAS BIBLIOGRÁFICAS}

1. Alikhan M, Rex D, Khan A, Rahmani E, Cummings O, Ulbright TM. Variable pathologic interpretation of columnar lined esophagus by general pathologists in community practice. Gastrointest Endosc 1999;50:23-6.

2. Baas IO, Mulder J-WR, Offerhaus GJA, Vogelstein B, Hamilton SR. An evaluation of six antibodies for immunohistochemistry of mutant p53 gene product in archival colorectal neoplasms. J Pathol 1994;172:5-12.

3. Bian Y-S, Osterheld M-C, Bosman FT, Benhattar J, Fontolliet C. p53 gene mutation and protein accumulation during neoplastic progression in Barrett's esophagus. Mod Pathol 2001;14:397-403.

4. Cameron AJ. Epidemiology of columnar-lined esophagus and adenocarcinoma. Gastroenterol Clin North Am 1997;26:487-94

5. Casson AG, Manolopoulos B, Troster M, Kerkvliet N, O’Malley F, Inculet R, Finley $\mathrm{R}$, Roth JA. Clinical implications of $\mathrm{p} 53$ gene mutation in the progression of Barrett's epithelium to invasive esophageal cancer. Am J Surg 1994;167:52-7.

6. Cross SS. Grading and scoring in histopathology. Histopathology 1998; 33:99-106.

7. Daly JM, Fry WA, Little AG, Winchester DP, Mckee RF, Stewart AK, Fremgen AM Esophageal cancer: results of an American College of Surgeons patient care evaluation study. J Am Coll Surg 2000;190:548-59.

8. DeMeester SR, DeMeester TR. Columnar mucosa and intestinal metaplasia of the esophagus: fifty years of controversy. Ann Surg 2000;231:303-21.

9. Fitzpatrick FA. Inflammation, carcinogenesis and cancer. Int Immunopharmacol 2001;1:1651-67.

10. Geboes K, Van Eyken P. The diagnosis of dysplasia and malignancy in Barrett's oesophagus. Histopathology 2000;37:99-107.

11. Hall PA, Lane DP. p53 in tumour pathology: can we trust immunohistochemistry? - revisited! J Pathol 1994:172:1-4.

12. Hardwick RH, Shepherd NA, Moorghen M, Newcomb PV, Alderson D. Adenocarcinom arising in Barrett's oesophagus: evidence for the participation of $\mathrm{p} 53$ dysfunction in the dysplasia/carcinoma sequence. Gut 1994;35:764-8.

13. Hofseth LJ, Saito S, Hussain SP, Espey MG, Miranda KM, Araki Y, Jhappan C, Higashimoto Y, He P, Linke SP, Quezado MM, Zurer I, Rotter V, Wink DA, Appella E, Harris CC. Nitric oxide-induced cellular stress and p53 activation in chronic inflammation. Proc Natl Acad Sci USA 2003;100:143-8.

14. Hulscher JBF, Haringsma J, BenraadT J, Offerhaus GJA, Kate FJW, Baak JPA, Tytgat GNJ, Van Lanschot JJB. Comprehensive Cancer Centre Amsterdam Barrett Advisory Committee: first results. Neth J Med 2001;58:3-8

15. Illueca C, Llombart-Bosch A, Ferrando Cucarella J. Factores pronósticos en el esófago de Barrett: estudio inmunohistoquímico y morfométrico de 120 casos. Rev Esp Enferm Dig 2000;92:726-31.

16. Ireland AP, Clark GWB, DeMeester TR. Barrett's esophagus: the significance of p53 in clinical practice. Ann Surg 1997;225:17-30.

17. Krishnadath KK, Tilanus HW, Blankenstein MV, Bosman FT, Mulder AH. Accumulation of p53 protein in normal, dysplastic, and neoplastic Barrett's oesophagus. J Pathol $1995 ; 175: 175-80$

18. Krishnadath KK, Reid BJ, Wang KK. Biomarkers in Barrett esophagus. Mayo Clin Proc 2001;76:438-46.

19. Kubba AK, Poole NA, Watson A. Role of p53 assessment in management of Barrett's esophagus. Dig Dis Sci 1999;44:659-67.

20. Lopes CV, Pereira-Lima JC, Hartmann AA, Tonelotto E. Reprodutibilidade no diagnóstico histopatológico do esôfago de Barrett na presença de metaplasia intestinal focal em biópsias endoscópicas. GED Gastroenterol Endosc Dig 2004;23:47-52.

21. Lopes CV, Pereira-Lima JC, Hartmann AA, Tonelotto E, Salgado K. Displasia no esôfago de Barrett - concordância intra e interobservador no diagnóstico histopatológico. Arq Gastroenterol 2004;41:5-9.
22. Lopes CV, Pereira-Lima JC, Hartmann AA. Correlation between alcian blue-periodic acid-schiff stain and immunohistochemical expression of mucin 2 in Barretts oesophagus. Histopathology 2004;45:198-9.

23. McManus DT, Olaru A, Meltzer SJ. Biomarkers of esophageal adenocarcinoma and Barrett's esophagus. Cancer Res 2004;64:1561-9.

24. Mighell AJ, Hume WJ, Robinson PA. An overview of the complexities and subtleties of immunohistochemistry. Oral Dis 1998;4:217-23.

25. Montgomery E, Bronner MP, Goldblum JR, Greenson JK, Haber MM, Hart J, Lamps LW, Lauwers GY, Lazenby AJ, Lewin DN, Robert ME, Toledano AY, ShyrY, Washington $\mathrm{K}$. Reproducibility of the diagnosis of dysplasia in Barrett esophagus: a reaffirmation. Hum Pathol 2001;32:368-78

26. Morales TG, Sampliner RE. Barrett's esophagus: update on screening, surveillance, and treatment. Arch Intern Med 1999;159:1411-6.

27. O'Connor JB, Falk GW, Richter JE. The incidence of adenocarcinoma and dysplasia in Barrett's esophagus. Am J Gastroenterol 1999;94:2037-42.

28. Polkowski W, Baak JPA, Van Lanschot JJB, Meijer GA, Schuurmans LT, Ten Kate FJW, Obertop H, Offerhaus GJA. Clinical decision making in Barrett's oesophagus can be supported by computerized immunoquantitation and morphometry of features associated with proliferation and differentiation. J Pathol 1998;184:161-8.

29. Reid BJ, Haggitt RC, Rubin CE, Roth G, Surawicz CM, Van Belle G, Lewin K, Weinstein WM, Antonioli DA, Goldman H. Observer variation in the diagnosis of dysplasia in Barrett's esophagus. Hum Pathol 1988;19:166-78.

30. Reid BJ, Blount PL, Rabinovitch PS. Biomarkers in Barrett's esophagus. Gastrointest Endosc Clin N Am 2003;13:369-97.

31. Sampliner RE, The Practice Parameters Committee of the American College of Gastroenterology. Updated guidelines for the diagnosis, surveillance, and therapy of Barrett's esophagus. Am J Gastroenterol 2002;97:1888-95.

32. Symmans PJ, Linehan JM, Brito MJ, Filipe MI. p53 expression in Barrett's oesophagus, dysplasia, and adenocarcinoma using antibody DO-7. J Pathol 1994;173:221-6.

33. Weston AP, Badr AS, Hassanein RS. Prospective multivariate analysis of clinical, endoscopic, and histological factors predictive of the development of Barrett's multifocal high-grade dysplasia or adenocarcinoma. Am J Gastroenterol 1999;94:3413-9.

34. Wu TT, Watanabe T, Heitmiller R, Zahurak M, Forastiere AA, Hamilton SR Genetic alterations in Barrett esophagus and adenocarcinomas of the esophagus and esophagogastric junction region. Am J Pathol 1998;152:287-94. 